\title{
Is the Prevalence of the Deficit Syndrome in Schizophrenia Higher than Estimated? Results of a Meta-Analysis
}

\author{
Álvaro López-Díaz', Ignacio Lara ${ }^{1}$, and Guillermo Lahera ${ }^{2} \bowtie$ \\ ${ }^{1}$ Mental Health Clinical Management Unit Virgen Macarena University Hospital, Seville, Spain \\ ${ }^{2}$ Department of Medicine and Medical Specialties University of Alcalá, IryCIS, CIBERSAM, Madrid, Spain
}

The primary and enduring presence of negative symptoms observed in a relatively homogeneous subgroup of patients with schizophrenia led to the concept of deficit syndrome (DS). Until date, it is considered that $20-25 \%$ of schizophrenia cohorts have DS. The aim of this meta-analysis was to determine the current prevalence of DS, including international and most recent studies. Thirteen observational studies met the inclusion criteria, comprising 2092 patients from eight countries. Pooled proportion of the DS subgroup was $32.64 \%$, higher than previously reported. Based on our outcomes, up to one-third of patients with schizophrenia might have idiopathic and stable negative symptoms. This significant proportion of patients should be well represented in clinical trial's samples.

Psychiatry Investig 2018;15(1):94-98

Key Words Deficit syndrome, Negative symptoms, Primary negative symptoms, Deficit Schizophrenia, Schizophrenia.

\section{INTRODUCTION}

Negative symptoms are a heterogeneous clinical construct which constitute a core psychopathological domain of schizophrenia. ${ }^{1}$ They can be stable or transient and have been divided into primary, when they are intrinsic to the illness, or secondary, if they originated from confounding conditions (medication side effects, psychotic symptoms, depression, substance abuse, or environmental deprivation). ${ }^{1,2}$ Nonetheless, they are associated with marked functional disability, diminution of quality of life and increased burden on patients' carers. $^{3-6}$

The primary and enduring presence of negative symptoms observed in a relatively homogeneous subgroup of patients with schizophrenia led to the concept of the deficit syndrome (DS). ${ }^{2}$ Studies comparing differences between a DS group and a non-deficit group have contributed to the hypothesis that deficit schizophrenia could be a separate disease. ${ }^{7-10}$ However, de-

Received: January 18, 2017 Revised: March 23, 2017

Accepted: April 27, 2017 Available online: November 29, 2017

$\triangle$ Correspondence: Guillermo Lahera, MD, PhD

Department of Medicine and Medical Specialties University of Alcalá, IRyCIS, CIBERSAM Ctra. Madrid-Barcelona, km. 33,600 28805 Alcalá de Henares, Madrid, Spain

Tel: +34 918854883, Fax: +34 918816264 , E-mail: guillermo.lahera@uah.es

(c) This is an Open Access article distributed under the terms of the Creative Commons Attribution Non-Commercial License (http://creativecommons.org/licenses/bync/4.0) which permits unrestricted non-commercial use, distribution, and reproduction in any medium, provided the original work is properly cited. spite evidence suggesting that DS represents a valid taxon, it has not been considered either as a subtype or as an independent psychotic disorder in the fifth Diagnostic and Statistical Manual of Mental Disorders. ${ }^{11}$

Distinguishing primary from secondary negative symptoms in DS requires good clinical care and bears important therapeutic implications. ${ }^{12}$ Although there are several specific tools for the assessment of negative symptoms, the Schedule for the Deficit Syndrome (SDS) ${ }^{13}$ is considered the gold-standard instrument to evaluate those symptoms as primary and stable. $^{12}$ This scale defines DS on the basis of clinical criteria extracted from patients' past and present mental states. It consists of a semi-structured interview that also collects information from relatives and allows an operative categorisation between deficit and non-deficit groups. ${ }^{14}$ According to this methodology, about $20-25 \%$ of schizophrenia cohorts have DS. ${ }^{1,15}$

When the SDS is not available (usually it is not feasible in large epidemiological samples), the Proxy for the Deficit Syndrome (PDS) has been proposed as an alternative method for assessment. ${ }^{16}$ PDS classifies the subjects into deficit or non-deficit groups based on a specific profile on the Brief Psychiatric Rating Scale (BPRS) or the Positive and Negative Syndrome Scale (PANSS). ${ }^{17}$ However, DS proportions vary from $2 \%$ to $34 \%$ in different studies when the PDS scale is used, ${ }^{18}$ which indicates that it might not be a reliable instrument for an accu- 
rate categorisation. ${ }^{14,19,20}$

To our knowledge, the epidemiological rate of deficit schizophrenia has not been calculated using a meta-analytic framework and the reference data available in the literature correspond to estimates conducted by SDS authors in the United States (mostly during the 1990s). 10,16,21 Therefore, the aim of this meta-analysis was to determine the current prevalence of DS (assessed through SDS), including international and most recent studies.

\section{METHODS}

\section{Search strategy}

The methodology was based on the guidelines outlined by the Meta-analysis of Observational Studies in Epidemiology (MOOSE) recommendations. ${ }^{22}$ To identify the relevant literature, a combined search in PubMed, Medline, EMBASE and Google Scholar was conducted. Considering that the evaluated period could condition the outcomes and with the aim of obtaining a prevalence rate as close to the present as possible, we decided to limit the search for articles to a recent period in time between 2010 and 2015. We also carried out a handsearch for citations from the retrieved studies. The following keywords were used: 'schedule for the deficit syndrome' combined with 'deficit schizophrenia', 'deficit syndrome', 'negative symptoms'.

\section{Inclusion and exclusion criteria}

The first author (ÁL-D) screened the titles and abstracts, then all authors independently reviewed the full texts of the selected articles. Studies were included if they met all of the following criteria: 1) written or translated in English; 2) published in a peer-reviewed journal; 3) related to any schizophrenia topic with a deficit/non-deficit categorisation; 4) authors did not use purposive sampling unless they reported in the article the proportion of patients with DS among the total sample; and 5) SDS was the instrument employed to enabling the diagnosis of DS given that is the gold-standard measure for separating primary and secondary negative symptoms in deficit schizophrenia. In cases where the samples overlapped, the article with the largest sample size was included. Reviews, editorials, opinion articles and research studies with fewer than 10 subjects were excluded.

\section{Outcome measure, data extraction and quality assessment}

In this epidemiological analysis, the standardised outcome measure was the proportion of patients with deficit schizophrenia, therefore only data concerning the prevalence of DS among the sample of each study were extracted. Other clinical and demographic variables (such as gender, season of birth, age of onset, duration of illness and symptoms severity) were not considered. Although there is no clear consensus on the method to be used to appraise quality assessment in observational studies, ${ }^{23}$ we used a simple objective rating system based on the meta-analysis conducted by Paulson et al. ${ }^{24}$ Studies were thus coded on a scale of 0 to 10 , with 2 points each assigned for recruitment strategies (probability vs nonprobability sampling), inclusion and exclusion criteria (clearly stated or not), ethnic diversity ( $\geq 20 \%$ minority), educational diversity $(\leq 80 \%$ at 1 educational level) and the response rate (reported at $\geq 60 \%)^{24}$ Two independent reviewers (ÁL-D and IL) performed the quality assessment, with a third reviewer (GL) consulted in case of any disagreement.

\section{Data analysis}

A meta-analysis on the selected papers was conducted to obtain an overall weighted prevalence of DS. Data from each individual study were pooled using a DerSimonian-Laird proportion meta-analysis. ${ }^{25}$ As it was not clear whether the outcome measure was affected by the factors used in the quality assessment, weighting of the included articles according to that rating system was not performed. However, a second analysis was conducted excluding those studies with the lowest quality scores ( $<6$ points) to determine whether potential methodological weaknesses could have influenced the meta-analytic estimates. Statistical procedures were performed with MedCalc Statistical Software version 15.8 (MedCalc Software, Mariakerke, Belgium). Data extraction and analysis were carried out by the main author (ÁL-D) and checked by the others.

\section{RESULTS}

\section{Search results}

The initial literature search yielded a total of 95 peer-reviewed articles published in English language journals. A subset of 33 articles was selected for consideration after screening the titles and abstracts. These potentially relevant studies were fulltext reviewed to determine eligibility and to extract prevalence data of DS. Finally, 13 articles met the inclusion criteria (Figure 1). ${ }^{15,26-37}$ The studies comprised 2,092 patients from eight countries (Brazil, China, France, Hungary, Italy, Spain, Turkey, and the United States), with subjects aged between 18 and 69 years old. The quality assessment of the articles yielded scores rated between 4 and 8 points (Table 1 ).

As heterogeneity was invariably high, random-effects metaanalyses were performed on the estimates to generate summary values. The pooled proportion of the DS subgroup was $32.64 \%$ (95\% CI=25.39 to 40.34) (Figure 2). Removing the studies with the lowest quality ratings ( $<6$ points), the meta- 
analytical estimate of DS varied by only $0.58 \%$ (from $32.64 \%$ to $33.22 \%$ ). Therefore, the results remained essentially unchanged in direction and magnitude.

\section{Excluded studies}

A total of 82 studies did not meet the inclusion criteria (Figure 1). Sixty-seven articles covering reviews, meta-analysis, editorials, letters to the editors and studies with selective sampling or PDS categorisation were excluded. Two papers were refused because they imposed strict patients inclusion criteria and two others were rejected given that the research was focused on first-episode psychosis. Eleven articles were omit- ted because it was found that samples may not have been entirely independent of each other. Of those, five corresponded to studies carried out at the Maryland Psychiatric Research Center.

\section{DISCUSSION}

The proportion of deficit schizophrenia found in this metaanalysis (32.64\%) was higher than that originally reported by the authors of the SDS scale (20-25\%). This may be because we included articles from several countries in which the profiles of the attended population and the types of received treat-

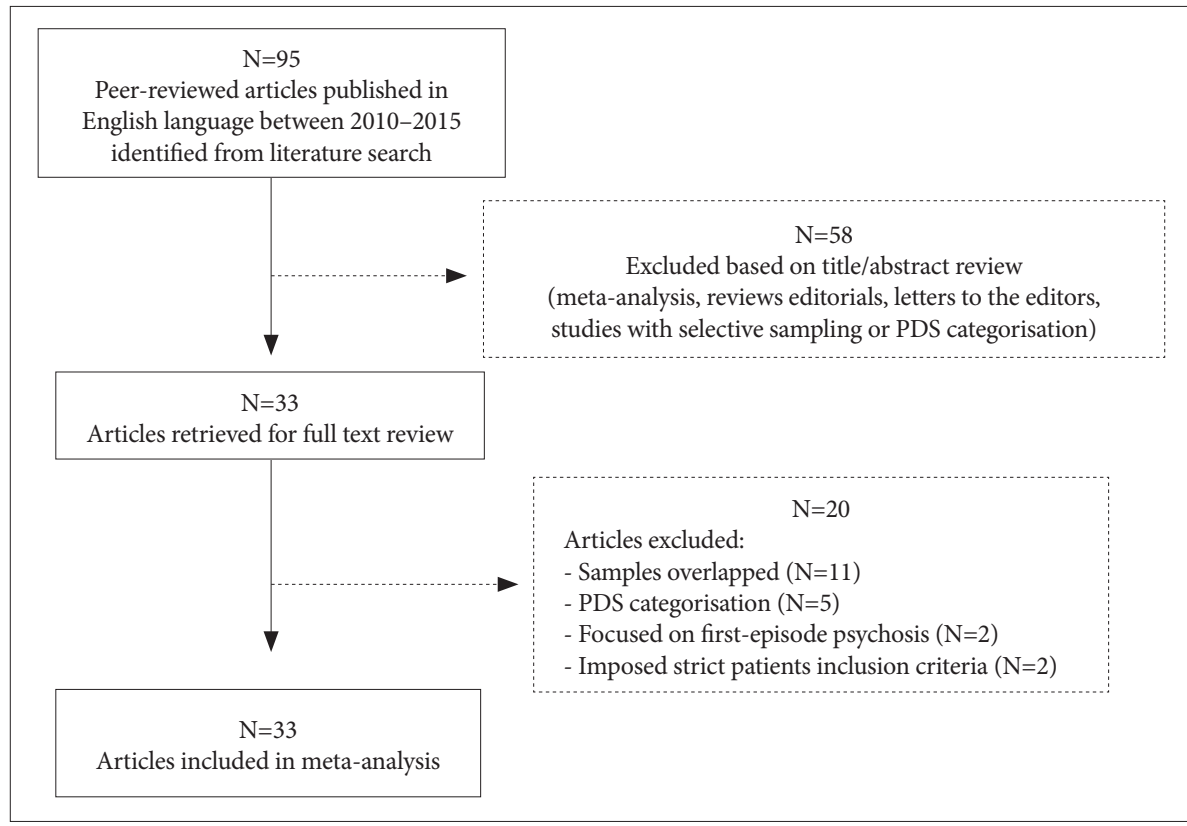

Figure 1. Flow chart showing the articleidentification process.

Table 1. Quality assessment and characteristics of included studies

\begin{tabular}{|c|c|c|c|c|c|}
\hline Author & Year published & Quality score & DS (\%) & Country & $\mathrm{HDI}^{*}$ \\
\hline Ahmed et al. ${ }^{11}$ & 2015 & 8 & 19.39 & USA & 0.915 \\
\hline Dantas et al. ${ }^{26}$ & 2011 & 6 & 34.11 & Brazil & 0.755 \\
\hline Ekinci et al. ${ }^{27}$ & 2012 & 6 & 33.05 & Turkey & 0.761 \\
\hline Kitis et al. ${ }^{28}$ & 2012 & 6 & 37.93 & Turkey & 0.761 \\
\hline Kösger et al. ${ }^{29}$ & 2014 & 6 & 42.25 & Turkey & 0.761 \\
\hline Mete et al. ${ }^{30}$ & 2015 & 6 & 35.45 & Turkey & 0.761 \\
\hline Nkam et al. ${ }^{31}$ & 2010 & 4 & 21.56 & France & 0.888 \\
\hline Rethelyi et al. ${ }^{32}$ & 2010 & 6 & 54.64 & Hungary & 0.828 \\
\hline Santos et al. ${ }^{33}$ & 2010 & 6 & 27.15 & Spain & 0.876 \\
\hline Scala et al. ${ }^{34}$ & 2014 & 4 & 27.50 & Italy & 0.873 \\
\hline Szendi et al. ${ }^{35}$ & 2010 & 6 & 28.00 & Hungary & 0.828 \\
\hline Vogel et al. ${ }^{36}$ & 2013 & 8 & 22.38 & USA & 0.915 \\
\hline Yu et al..$^{37}$ & 2015 & 4 & 41.23 & China & 0.727 \\
\hline
\end{tabular}

*United Nations Development Programme. Human Development Report 2015- "Rethinking Work for Human Development". http://hdr. undp.org/en/2015-report (retrieved 14 December 2015). DS: deficit syndrome, HDI: Human Development Index 


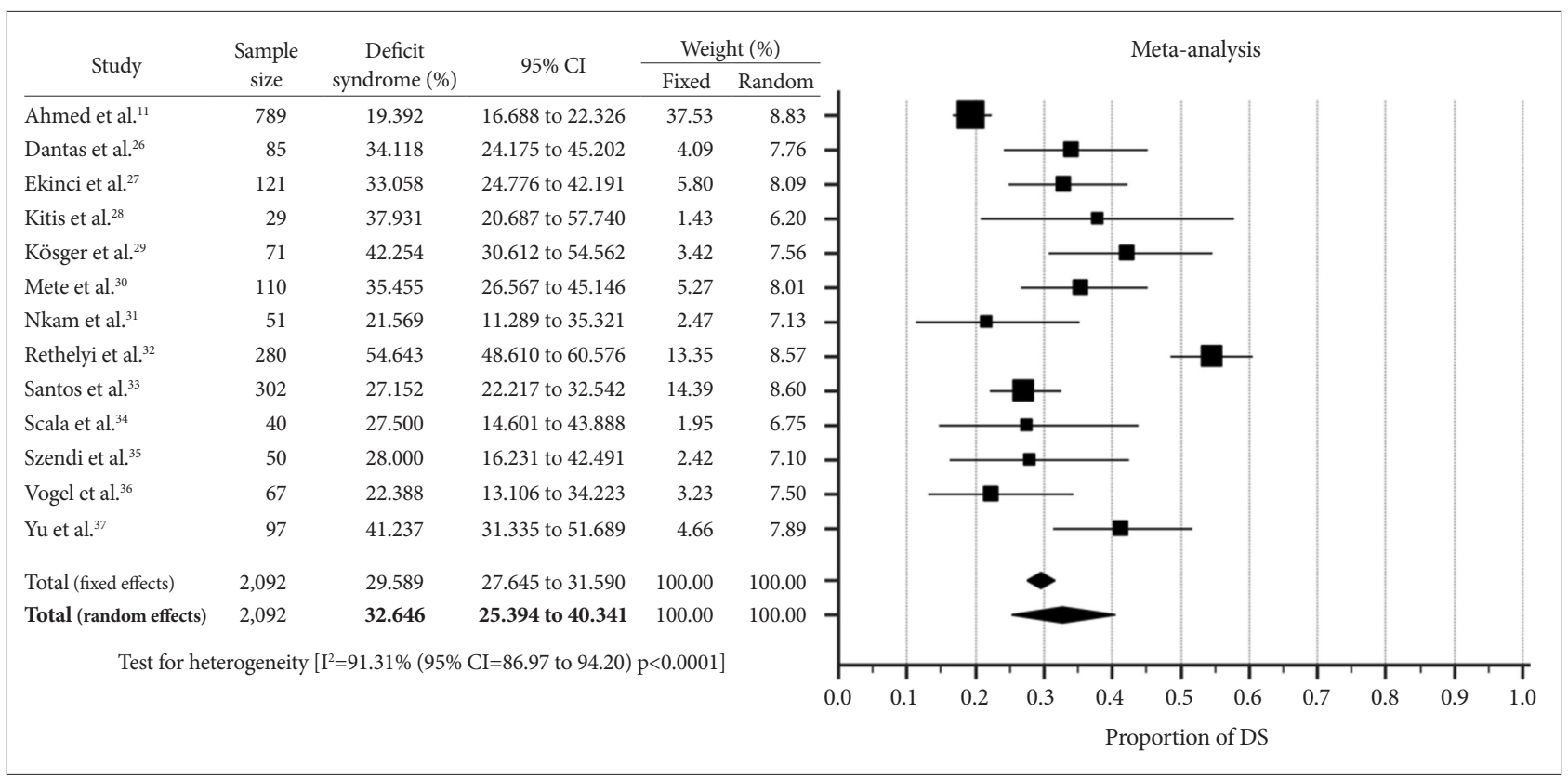

Figure 2. Pooled prevalence of the deficit syndrome in schizophrenia by random effects meta-analysis. Cl: confidence interval, DS: deficit syndrome.

ment could have been different. This fact can be interpreted at the same time as a methodological limitation and as one of the strengths of this research since it provides a more comprehensive overview of the worldwide prevalence of DS. Thus, we have been able to observe that studies carried out in countries with lower Human Development Index ${ }^{38}$ were those that yielded higher DS frequencies (Table 1). Furthermore, by reviewing other meta-analyses related to DS that included earlier articles than those examined by us, we found that deficit schizophrenia rates were in many cases also higher than expected. ${ }^{19,20,39}$

Based on our outcomes, up to one-third of patients with schizophrenia might have idiopathic and stable negative symptoms for which no effective treatment exists yet. ${ }^{40,41}$ Hence, this high prevalence of DS should steer clinicians towards focusing more on the task of distinguishing between primary and secondary negative symptoms, as well as trying to minimise secondary causes. This difficult task might often be neglected and could lead to false optimism in the interpretation of some clinical trials, where observed improvement in terms of negative symptomatology ${ }^{42}$ would be down to nothing more than reductions in secondary sources. ${ }^{15}$

Moreover, it is also important to stress that the term DS should be applied only to patients meeting the SDS diagnostic criteria, ${ }^{9}$ and its assessment precises a methodology that is not usually feasible for randomised controlled trials in schizophrenia. ${ }^{43}$ In those, measures of negative symptoms rely upon the PANSS negative factor or the BPRS negative symptom subscale or the Scale for the Assessment of Negative Symptoms (SANS).
Such scales could be useful for detecting subjects with persistent negative symptoms ${ }^{44}$ but are not appropriate for categorising deficit schizophrenia. For this reason, patients with DS have not been well identified in those studies and therefore outcomes may not be generalisable for that subgroup.

In a personalised medicine paradigm, subjects with deficit schizophrenia are likely to benefit from specific interventions, and this can only be achieved by conducting clinical trials with representative samples of this subset of patients. Our contribution is to indicate that the prevalence of DS, according to the most recent international studies, may be higher than the estimated one. This could encourage many investigators to carry out further studies which help to deepen the understanding of primary negative symptoms as well as the development of specific treatments for them, undoubtedly one of the greatest challenges in schizophrenia research.

\section{REFERENCES}

1. Kirkpatrick B, Fenton WS, Carpenter WT Jr, Marder SR. The NIMHMATRICS consensus statement on negative symptoms. Schizophr Bull 2006;32:214-219.

2. Carpenter WT Jr, Heinrichs DW, Wagman AM. Deficit and nondeficit forms of schizophrenia: the concept. Am J Psychiatry 1998;145:578-583.

3. Rabinowitz J, Levine SZ, Garibaldi G, Bugarski-Kirola D, Berardo CG, Kapur S. Negative symptoms have greater impact on functioning than positive symptoms in schizophrenia: analysis of CATIE data. Schizophr Res 2012;137:147-150.

4. Eack SM, Newhill CE. Psychiatric symptoms and quality of life in schizophrenia: a meta-analysis. Schizophr Bull 2007;33:1225-1237.

5. Mitsonis C, Voussoura E, Dimopoulos N, Psarra V, Kararizou E, Latzouraki E, et al. Factors associated with caregiver psychological distress in chronic schizophrenia. Soc Psychiatry Psychiatr Epidemiol 2012;47: 
331-337.

6. Ochoa S, Vilaplana M, Haro JM, Villalta-Gil V, Martínez F, Negredo MC, et al. the NEDES Group. Do needs, symptoms or disability of outpatients with schizophrenia influence family burden? Soc Psychiatry Psychiatr Epidemiol 2008;43:612-618.

7. Kirkpatrick B, Galderisi S. Deficit schizophrenia: an update. World Psychiatry 2008;7:143-147.

8. Mucci A, Galderisi S, Kirkpatrick B, Bucci P, Volpe U, Merlotti E, et al. Double dissociation of N1 and P3 abnormalities in deficit and nondeficit schizophrenia. Schizophr Res 2007;92:252-261.

9. Galderisi S, Maj M, Mucci A, Cassano GB, Invernizzi G, Rossi A, et al. Historical, psychopathological, neurological, and neuropsychological aspects of deficit schizophrenia: a multicenter study. Am J Psychiatry 2002;159:983-990.

10. Kirkpatrick B, Buchanan RW, Ross DE, Carpenter WT Jr. A Separate Disease Within the Syndrome of Schizophrenia. Arch Gen Psychiatry 2001;58:165-171.

11. Ahmed AO, Strauss GP, Buchanan RW, Kirkpatrick B, Carpenter WT. Are negative symptoms dimensional or categorical? Detection and validation of deficit schizophrenia with taxometric and latent variable mixture models. Schizophr Bull 2015;41:879-891.

12. Mucci A, Merlotti E, Ucok A, Aleman A, Galderisi S. Primary and persistent negative symptoms: concepts, assessments and neurobiological bases. Schizophr Res 2017;186:19-28.

13. Kirkpatrick B, Buchanan RW, McKenny PD, Alphs LD, Carpenter WT Jr. The schedule for the deficit syndrome: an instrument for research in schizophrenia. Psychiatry Res 1989;30:119-123.

14. Galderisi S, Maj M. Deficit schizophrenia: an overview of clinical, biological and treatment aspects. Eur Psychiatry 2009;24:493-500.

15. Carpenter WT, Kirkpatrick B. Concepts and methods when considering negative symptom course. Psychol Med 2015;45:2135-2136.

16. Kirkpatrick B, Buchanan RW, Breier A, Carpenter WT Jr. Case identification and stability of the deficit syndrome of schizophrenia. Psychiatry Res 1993;47:47-56.

17. Goetz RR, Corcoran C, Yale S, Stanford AD, Kimhy D, Amador X, Malaspina D. Validity of a 'proxy' for the deficit syndrome derived from the Positive and Negative Syndrome Scale (PANSS). Schizophr Res 2007; 93:169-177.

18. Kalisz A, Cechnicki A. The stability of negative syndrome, persistent negative syndrome and deficit syndrome in a twenty-year follow-up study of schizophrenia patients. Psychiatry Res 2016;238:236-241.

19. Cohen AS, Brown LA, Minor KS. The psychiatric symptomatology of deficit schizophrenia: a meta-analysis. Schizophr Res 2010;118:122-127.

20. Roy MA, Maziade M, Labbé A, Mérette C. Male gender is associated with deficit schizophrenia: a meta-analysis. Schizophr Res 2001;47:141147.

21. Kirkpatrick B, Ram R, Bromet E. The deficit syndrome in the suffolk county mental health project. Schizophr Res 1996;22:119-126.

22. Stroup DF, Berlin JA, Morton SC, Olkin I, Williamson GD, Rennie D, et al. Meta-analysis of observational studies in epidemiology: a proposal for reporting. Meta-analysis Of Observational Studies in Epidemiology (MOOSE) group. JAMA 2000;283:2008-2012.

23. Shamliyan T, Kane RL, Jansen S. Systematic reviews synthesized evidence without consistent quality assessment of primary studies examining epidemiology of chronic diseases. J Clin Epidemiol 2012;65:610618.

24. Paulson JF, Bazemore SD. Prenatal and postpartum depression in fathers and its association with maternal depression: a meta-analysis. JAMA 2010;303:1961-1969.

25. DerSimonian R, Kacker R. Random-effects model for meta-analysis of clinical trials: an update. Contemp Clin Trials 2007;28:105-114.

26. Dantas CR, Barros BR, Fernandes PT, Li LM, Banzato CEM. Insight controlled for cognition in deficit and nondeficit schizophrenia. Schizophr Res 2011;128:124-126.

27. Ekinci O, Albayrak Y, Ekinci A. Cognitive Insight and Its Relationship with Symptoms in Deficit and Nondeficit Schizophrenia. J Nerv Ment Dis 2012;200:44-50.

28. Kitis O, Ozalay O, Zengin EB, Haznedaroglu D, Eker MC, Yalvac D, et al. Reduced left uncinate fasciculus fractional anisotropy in deficit schizophrenia but not in non-deficit schizophrenia. Psychiatry Clin Neurosci 2012;66:34-43.

29. Kösger F, Sahin H, Essizoglu A, Aksaray G. Insight and social functioning in deficit and nondeficit schizophrenia. Turk Psikiyatri Derg 2014; 25:157-162.

30. Mete L, Sarıkaya Ö, Erol A. The relationship of deficit syndrome with clinical symptoms, summer births and heritability in patients with schizophrenia. Turk Psikiyatri Derg 2015;26:229-235.

31. Nkam I, Bocca M, Denise P, Paoletti X, Dollfus S, Levillain D, et al. Impaired Smooth Pursuit in Schizophrenia Results from Prediction Impairment Only. Biol Psychiatry 2010;67:992-997.

32. Réthelyi JM, Bakker SC, Polgár P, Czobor P, Strengman E, Pásztor PI, et al. Association study of NRG1, DTNBP1, RGS4, G72/G30, and PIP5K2A with schizophrenia and symptom severity in a Hungarian sample. Am J Med Genet B Neuropsychiatr Genet 2010;153B:792-801.

33. Santos JL, Sánchez-Morla EM, Aparicio A, García-Jiménez MÁ, Villanueva C, Martínez-Vizcaíno V, et al. P50 gating in deficit and nondeficit schizophrenia. Schizophr Res 2010;119:183-190.

34. Scala S, Lasalvia A, Seidman LJ, Cristofalo D, Bonetto C, Ruggeri M. Executive functioning and psychopathological profile in relatives of individuals with deficit v. non-deficit schizophrenia: a pilot study. Epidemiol Psychiatr Sci 2014;23:85-97.

35. Szendi I, Racsmány M, Cimmer C, Csifcsák G, Kovács ZA, Szekeres G, et al. Two subgroups of schizophrenia identified by systematic cognitive neuropsychiatric mapping. Eur Arch Psychiatry Clin Neurosci 2010;260: 257-266.

36. Vogel SJ, Strauss GP, Allen DN. Using negative feedback to guide behavior: impairments on the first 4 cards of the wisconsin card sorting test predict negative symptoms of schizophrenia. Schizophr Res 2013;151: 97-101.

37. Yu M, Tang X, Wang X, Zhang X, Zhang X, Sha W, et al. Neurocognitive impairments in deficit and non-deficit schizophrenia and their relationships with symptom dimensions and other clinical variables. PLoS One 2015; 10:e0138357.

38. Selim J. Human Development Report: Rethinking work for human development. United Nations Development Programme. Available at: http://hdr.undp.org/en/2015-report. Accesed December 14, 2015.

39. Messias E, Kirkpatrick B, Bromet E, Ross D, Buchanan RW, Carpenter WT Jr, et al. Summer birth and deficit schizophrenia: a pooled analysis from six countries. Arch Gen Psychiatry 2014;61:985-989.

40. Aleman A, Lincoln TM, Bruggeman R, Melle I, Arends J, Arango C, et al. Treatment of negative symptoms: where do we stand, and where do we go? Schizophr Res 2017;186:55-62.

41. Fusar-Poli P, Papanastasiou E, Stahl D, Rocchetti M, Carpenter W, Shergill S, et al. Treatments of negative symptoms in schizophrenia: metaanalysis of 168 randomized placebo-controlled trials. Schizophr Bull 2015;41:892-899.

42. Savill M, Banks C, Khanom H, Priebe S. Do negative symptoms of schizophrenia change over time? A meta-analysis of longitudinal data. Psychol Med 2015;45:1613-1627.

43. Galderisi S, Färden A, Kaiser S. Dissecting negative symptoms of schizophrenia: history, assessment, pathophysiological mechanisms and treatment. Schizophr Res 2017;186:1-2.

44. Buchanan RW. Persistent negative symptoms in schizophrenia: an overview. Schizophr Bull 2007;33:1013-1022. 